The Geneva Papers on Risk and Insurance, 14 (No. 50, January 1989), 11-25

\title{
Accidents and the Allocation of Legal Costs with an Uninformed Court
}

\author{
by H.S. E. Gravelle*
}

\section{Introduction}

An individual (the defendant) engages in an activity which carries the risk of an accident. The accident will impose a loss on another individual (the plaintiff). The defendant can reduce the probability of the accident by expenditure on safety precautions. If the two individuals can negotiate before the defendant chooses his care level the Coase Theorem suggests that the legal liability regime does not affect efficiency. ${ }^{1}$ The parties will make an efficient bargain about the level of care. It does not matter whether the defendant is strictly liable, or whether there is a negligence rule, or whether the plaintiff must bear all the accident losses. If the parties cannot bargain about the care level the liability regime will affect efficiency, but a rule imposing strict liability on the defendant will lead him to take an efficient amount of care. ${ }^{2}$

The conclusion that strict liability leads to efficiency rests on two implicit assumptions: enforcement of the plaintiff's rights is costless and the court will award damages equal to his loss. Courts, however, are not omniscient and litigation costs are large in proportion to damages awarded. Because legal costs are large the parties have an incentive to settle before a trial. The magnitude of settlement and thus the defendant's incentive to take care, will depend on the size of the litigation costs, the way in which they would be allocated between plaintiff and defendant if a trial occurs and on the damages which an imperfectly informed court would award.

\footnotetext{
*Economics Department, Queen Mary College, University of London. I am grateful for comments received at the 14th Seminar of the European Group of Risk and Insurance Economists in Geneva, September 1987 and to a referee.

1 We ignore the many qualifications, extensions and caveats in the enormous literature stimulated by Coase [1960].

2 A negligence rule would also produce efficiency provided that the due care or negligence standard was appropriately fixed and provided that the defendant's decision to indulge in the risky activity was unaffected by his legal obligations to the plaintiff (see Polinsky [1980]).
} 
This paper examines the efficiency implications of two methods of allocating litigation costs between the parties. Under the American rule each party bears his own legal costs irrespective of the outcome of the trial. The British rule makes the allocation of the legal costs between the parties dependant on the outcome of the trial. The effects of the legal cost allocation rules on the post-accident settlement offers, the care taken by the defendant, the accident probability and the parties' expected utilities are considered.$^{3}$ I show that a choice between the two rules on welfare grounds would require very detailed information about preferences and the productivity of care.

\section{Assumptions, definitions and notation}

The defendant is engaged in an activity which may lead to an accident imposing a financial loss $\mathrm{L}$ on the plaintiff. By increasing expenditure on care $\mathrm{x}$ the defendant can reduce the probability of the accident $\pi(x)\left(\pi^{\prime}<0, \pi^{\prime \prime}>0\right)$. If an accident occurs the defendant is strictly liable for the loss imposed on the plaintiff.

\section{Bargaining}

The defendant will make the plaintiff a settlement offer $S$, which the plaintiff may accept or reject. ${ }^{4}$ If the offer is refused, there is a trial to ascertain the amount of damages $L_{J}$ to be paid by the defendant to the plaintiff. The assumption of a single take-or-leave-it offer is similar to those in many other models of trials. It simplifies the analysis, makes comparison with other papers easier and focuses attention on the effects of the litigation cost allocation rules.

\section{Allocation of legal costs}

The trial imposes legal costs of $C_{p}$ and $C_{D}$ on the plaintiff and defendant. Under the American system of allocating legal costs each party pays their own legal costs.

The British system makes the losing party pay the legal costs of the winner. In cases where the legal dispute is about a point of law the party who loses the legal argument

\footnotetext{
${ }^{3}$ Ordover [1981] examines the implications of costly litigation when the regime is negligence-contributory negligence, but does not compare the American and British legal cost allocation rules. Polinsky and Rubenfeld [1988] consider adjusting damage awards to alleviate the inefficiency caused by litigation costs under American cost allocation rules. In Simon [1984] legal costs are endogenous, the court has imperfect information and is decision is influenced by legal expenditures. Accident costs are fixed but the likelihood of an accident its endogenous. Brauetigan, Owen and Panzar [1984] analyse alternative legal cost shifting rules and their effect on litigation expenditures but do not draw any welfare conclusions about pre-trial behaviour. Shavell [1982a] examines four cost allocation rules and their effects on the likelihood of suits and settlements. This model differs from those in this paper in that there is no analysis of the welfare effect of cost allocation rules on the defendant's care level. Shavell [1982b] does consider the welfare implications of legal costs but only under American rules. Png [1987] examines efficiency in negligence cases and comments briefly on the British rules.
}

${ }^{4}$ A similar assumption is made by Bebchuk [1984] who also summarises alternative approaches to bargaining in legal disputes. 
must pay his opponent's costs. ${ }^{5}$ When, as in this paper, only the amount of damages is in dispute, the allocation of costs is determined by the defendant's payment into court. This is a sum of money deposited with the court's bankers at any time after the start of the action but before the trial judgement. The plaintiff is notified of the payment into court and acceptance of the payment by the plaintiff ends the action. The payment into court is not revealed to the judge or jury until after judgement is made. If the damages awarded against the defendant are less than or equal to the payment into court, the defendant can deduct his costs from the damages to be paid to the plaintiff. If the award exceeds the payment into court the defendant must also pay the plaintiff's legal costs. The defendant "loses" the case and must pay all the legal costs if his offer is less than the damages awarded by the court.

If we identify the defendant's settlement offer $S$ as the payment into court the amount the defendant pays the plaintiff if there is a trial under the British system is

$$
\begin{array}{lll}
L_{J}-C_{D} & \text { if } & L_{J} \leq S \\
L_{J}+C_{P} & \text { if } & L_{J}>S
\end{array}
$$

The British system imposes the total legal costs $\left(C_{D}+C_{P}\right)$ on the plaintiff if the judgement is less than or equal to the defendant's offer and on the defendant if the judgement exceeds the offer.

\section{Information about plaintiff's loss}

The plaintiff's accident loss is $L$. The court's award to the plaintiff $L_{J}$ is an unbiased estimate of $L$ :

$$
L_{J}=L+e, \quad E L_{J}=L
$$

The error $e=L_{J}-L$ in the court's estimate is concentrated on the interval $\left[e_{0}, e_{1}\right]$ with distribution function $F(e)$. It is assumed that $L+e_{0}>0$, so that the award is always positive and that $L+e_{1}>C_{P}$. If this latter inequality did not hold the plaintiff would never proceed to court under the American system and the defendant would never make a positive settlement offer. Both defendant and plaintiff know the accident loss $L$. The court can only make an unbiased estimate of the loss, so that plaintiff may be under or over-compensated by the court award.

\section{Preferences}

The defendant is risk neutral and has expected utility under the ith cost allocation rule

$$
V_{i D}=-x-\pi(x) H
$$

\footnotetext{
${ }^{5}$ In Shavell [1982a] the parties are in dispute about liability as well as damages. Shavell however assumes that in the British system the legal costs are awarded against the party losing the dispute about liability. This is so only if the plaintiff fails to establish that the defendant is liable or if the plaintiff wins the liability dispute and the defendant has made no payment into court. It is in fact possible for the plaintiff to have to pay all legal costs despite establishing the defendant's liability if the payment into court exceeds the damage awarded. Png [1987] adopts a similar specification to Shavell. The British rule is correctly specified in a pioneering analysis by Phillips, Hawkins and Flemming [1975] but they do not consider the wider efficiency aspects.
} 
which is maximised by choice of expenditure on care and by the settlement offer made if there is an accident. ${ }^{6}$ The defendant's offer $S$ minimes his expected post-accident costs $H$ which are his payment to the plaintiff and his legal costs. If the offer is accepted the defendant pays $S$ to the plaintiff. If the offer is rejected there is a trial and the defendant will face expected trial costs of the court award plus his share of legal costs. The expected cost of a trial to the defendant will depend on the method of allocating legal costs, the settlement offer and on the court award.

The plaintiff has expected utility under cost allocation rule $i$ of

$$
V_{i P}=(1-\pi) u(y)+\pi\left[(1-\theta) V_{i N T P}+\theta V_{i T P}\right]
$$

where $u(y)$ is utility if there is no accident, $\theta$ is the trial probability and $V_{i N T P}, V_{i T P}$ are expected utilities conditional on acceptance or rejection of the offer (i.e. conditional on no trial or trial). The plaintiff may be risk averse or risk neutral. ${ }^{7}$

\section{$\pi(x)$ \\ $y$ \\ $L$ \\ $u(y)$ \\ $C_{p}, C_{D}$ \\ $L_{J}$ \\ $e=L_{J}-L$ \\ $f(e), F(e)$ \\ $S^{a}, S^{b}$ \\ $V_{a T P}, V_{b T P}$ \\ $V_{i N T P}$ \\ $H^{a}, H^{b}$ \\ $r^{a}, r^{b}$ \\ $R^{a}, R^{b}$ \\ $\theta$ \\ $\lambda$ \\ $W$}

Notation and definitions
Expenditure on care by defendant.

Accident probability $\left(\pi^{\prime}<0, \pi^{\prime \prime}>0\right)$.

Endowed gross income of plaintiff.

Reduction in plaintiff's income caused by accident.

Plaintiff's utility function, concave in income $\left(u_{y}>0, u_{y y} \leq 0\right)$.

Legal costs of trial for plaintiff and defendant.

Damages awarded by court to plaintiff.

Court error in estimating plaintiff's loss.

Density and distribution function of court error.

Settlement offer made by defendant under American and British cost allocation rules.

Plaintiff's post-accident expected utility from trial under American and British cost allocation rules.

Plaintiff's post-accident expected utility if no trial (i.e. settlement offer accepted) under ith rules.

Defendant's post-accident expected payments (legal costs, settlement and damages) under American and British cost allocation rules.

Plaintiff's post-accident risk premia for trial under American and British cost allocation rules.

Plaintiff's risk premia for compound prospect of accident and trial under American and British rules.

Probability of a trial if there is an accident.

Distributional weight on defendant's expected utility $(\lambda>0)$.

Social welfare function.

\footnotetext{
${ }^{6}$ The defendant may be insured but if so we must assume that there is no moral hazard and the premium paid by the defendant varies with the amount of care exercised. rights.

${ }^{7}$ The plaintiff may be fully insured and the insurance company may have exercised its subrogation
} 


\section{Settlement offers under American and British cost allocation rules}

We will investigate the effects of a change in the rules for allocating legal costs on the behaviour of plaintiff and defendant. In particular we will examine the defendant's optimal post-accident settlement offer and the plaintiff's decision to accept or reject it.

If an accident occurs the plaintiff will suffer a loss of $L$ which is observed by the defendant. The defendant will make a settlement offer $S$ to the plaintiff. If the plaintiff accepts the offer, there is no trial and he has post-accident utility of

$$
V_{i N T P}=u(y+S-L)
$$

If the plaintiff rejects the offer there will be a trial and he will be awarded random damages of $L_{J}=L+e$. Under the American cost allocation rules his expected utility from a trial will be

$$
V_{a T P}=\int_{e_{0}}^{e_{1}} u\left(y-C_{p}+e\right) d F=V_{a T P}\left(y-C_{p}\right)
$$

since he has legal costs of $C_{p}$.

If the trial takes place under British rules the plaintiff's expected utility will be

$$
\begin{aligned}
V_{b T P} & =\int_{e_{0}}^{S-L} u\left(y-C_{p}-C_{D}+e\right) d F+\int_{S-L} e_{1} u(y+e) d F \\
& =V_{b T P}\left(y, S-L, C_{p}+C_{D}\right)
\end{aligned}
$$

since he bears legal costs of $C_{D}+C_{p}$ if $L+e \leq S$ and escapes payment of costs if $L+e>S$.

The defendant knows the loss $L$ and so the optimal settlement offer is easily characterised. Let $S^{a}$ and $S^{b}$ be the minimum offers which will be accepted by the plaintiff under American and British rules. ${ }^{8}$

Proposition 1. The settlement offer made by the defendant is equal to the minimum acceptable offer $\left(S^{a}\right.$ or $\left.S^{b}\right)$ under the prevailing cost allocation rules.

Proof: Under the American rules the offer will not exceed $S^{a}$ because $S^{a}$ would also be accepted and would cost the defendant less. By the concavity of $u(\cdot)$ and $V_{a N T P}=V_{a T P}$ we have $L-C_{P} \geq S^{a}$. If the offer is less than $S^{a}$, it is rejected and there is a trial which has an expected cost to the defendant of $E L_{J}+C_{D}=L+C_{D}>L-C_{p} \geq S^{a}$. Thus an offer $S<S^{a}$ leading to a trial is more costly than $S^{a}$. Similarly, under the British system the offer will not exceed $S^{b}$. The plaintiff's expected income with a trial if he has rejected $S^{b}$ is $y-F$ $\left(S^{b}-L\right)\left[C_{D}+C_{P}\right]$ since $E e=E L_{J}-L=0$ and the probability that $L_{J}=L+e \leq S$ is $F(S-L)$. By the concavity of $u(\cdot), y+S^{b}-L \leq y-F\left(S^{b}-L\right)\left[C_{P}+C_{D}\right]$. If the defendant makes an offer $S^{I}$ $<S^{b}$ it will be rejected and his expected payment at a trial will be $L-F\left(S^{I}-L\right)\left[C_{D}-C_{P}\right]>L-$ $F\left(S^{b}-L\right)\left[C_{D^{-}}-C_{P}\right]>S^{b}>S^{l}$. Hence the optimal offer is $S^{b}$.

\footnotetext{
${ }^{8}$ It is assumed that if the offer makes the plaintiff indifferent between acceptance and rejection he always accepts it and avoids the trial.
} 
Remarks: The plaintiff is always faced with an offer $\left(S^{a}\right.$ or $\left.S^{b}\right)$ which leaves him indifferent between acceptance or proceeding to trial. The offer is set so that there is a zero probability of a trial $(\theta=0)$ and the defendant reaps all the benefits of the two parties' legal cost savings.

The minimum acceptable offers $\left(S^{a}, S^{b}\right)$ are the defendant's post-accident costs (which influence his pre-accident care) and also the plaintiff's compensation for the accident. It is necessary to examine the influences on $S^{a}$ and $S^{b}$ and to attempt to determine the relative sizes of $S^{a}$ and $S^{b}$ in order to evaluate the alternative legal cost allocation rules.

We use $V_{i N T P}, V_{a T P}, V_{b T P}$ in (5) to (7) to define $S^{a}$ and $S^{b}$. The minimum acceptable offer under American rules is defined implicitly by

$$
V_{a T P}-V_{a N T P}=0
$$

Alternatively, the risk premium $r^{a}\left(y-C_{P}\right)$ for the prospect of a trial under American rules is given by $u\left(y-C_{p}-r^{a}\right)=V_{a T P}$ with $r^{a} \geq 0$ by the concavity of $u(\cdot)$. Using (8) we get

$$
S^{a}=L-C_{P}-r^{a}\left(y-C_{P}\right)=L-g^{a}\left(y-C_{P}, C_{P}\right)
$$

Under British rules $S^{b}$ is defined implicitly by

$$
V_{b T P}-V_{b N T P}=0
$$

The expected income of the plaintiff if there is a British trial is $y-F(S-L)\left[C_{p}+C_{D}\right]$. The risk premium $r^{b}\left(y, S-L, C_{p}+C_{D}\right)$ for this prospect is defined by

$$
u\left(y-F(S-L)\left[C_{P}+C_{D}\right]-r^{b}\right)-V_{b T P}=0
$$

and again $r^{b} \geq 0$ since $u(\cdot)$ is concave. Combining (10) and (11) gives an alternative definition of the minimum acceptable offer

$$
S^{b}-L+F\left(S^{b}-L\right)\left[C_{P}+C_{D}\right]+r^{b}\left(y, S-L, C_{P}+C_{D}\right)=0
$$

which can be solved for

$$
S^{b}=S^{b}\left(L, y, C_{P}+C_{D}\right)=L-g^{b}\left(y, C_{P}+C_{D}\right)
$$

The properties of the minimum acceptable offers are summarised in

\section{Proposition 2: The minimum acceptable offer functions $S^{i}(\cdot)$ satisfy}

(i) $S^{i}<L \quad(i=a, b)$

(ii) $\quad \partial S^{i} / \partial L=1 \quad(i=a, b)$

(iii) $\partial S i / \partial y>(=,<) 0$ as $u$ exhibits decreasing, constant or increasing absolute risk aversion

(iv) $\partial S^{a} / \partial C_{P}<0=\partial S^{a} / \partial C_{D}$

(v) $\partial S^{b} / \partial C_{P}=\partial S^{b} / \partial C_{D}<0$.

Proof: We have already established (i). Parts (ii), (iv) and ( $v$ ) follow easily from using the implicit function theorem on (8) and (10). Using the theorem on (8) and the definition of $r^{a}$ gives $\partial S^{a} / \partial y=\left[\partial V_{a T P} / \partial y-u_{y}\left(y+S^{a}-L\right)\right]\left[u_{y}\left(y+S^{a_{-}} L\right)\right]^{-1}=\partial r^{a} / \partial y$, and Theorems 1 and 2 of Pratt [1964] give (iii) for $i=a$. Proceeding similarly with (10) and (11) we see that 


$$
\begin{aligned}
\partial S^{b} / \partial y & \left.=-\left[1-\left(\partial V_{b T P} / \partial y\right)\left(u_{y}\left(y+S^{b}-L\right)\right)^{-1}\right]\left[1-\left(\partial V_{b T P} / \partial S\right) u_{y}\left(y+S^{b}-L\right)\right)^{-1}\right]^{-1} \\
& =-\left(\partial r^{b} / \partial y\right)\left[1-\left(\partial V_{b T P} / \partial S\right)\left(u_{y}\left(y+S^{b}-L\right)\right)^{-1}\right]^{-1}
\end{aligned}
$$

Since $\partial V_{b T P} / \partial S<0$, the sign of $\partial S^{b} / \partial y$ is the sign of $-\partial r^{b} / \partial y$ and application of Pratt's Theorems gives (iii) for $i=b$.

Remarks: Although the plaintiff has an undisputed legal right to be fully compensated for his loss by the defendant he always receives less than full compensation, whatever the legal cost allocation rules. The plaintiff's rights have to be exercised through a costly and uncertain legal system. The difference between the offer and the loss is $g^{i}=S^{i}-L$, which can be interpreted as the gain to the defendant arising because the courts are costly and their judgments are uncertain. This gain is the sum of the plaintiff's expected legal costs $\left(C_{P}\right.$ under American rules, $F\left[C_{P}+C_{D}\right]$ under British rules) and the risk premium $r^{i}$ which is the monetary equivalent of the cost of the risks imposed by an uncertain judgment on a risk averse plaintiff.

Variations in the accident damage $L$ lead to equal changes in the settlement offer and it is the defendant who gains or loses as $L$ is smaller or larger. If it was possible for the plaintiff to affect the probability distribution of damages, the fact that $\partial S^{i} / \partial L=1$ would leave him with no incentive to do so under either set of rules.

Increases in the plaintiff's legal costs $C_{P}$ make him more willing to settle out of court under both cost rules. Parts (iv) and ( $v$ ) of the proposition bring out an important difference between the two legal cost allocation rules regarding the defendant's costs $C_{D}$. Under the American system $C_{D}$ has no effect on $S^{a}$ whereas under the British system $C_{D}$ and $C_{P}$ have identical negative effects on the settlement offer. If the plaintiff and defendant have to pay any costs under the British system they will have to pay $C_{D}+C_{P}$ and it is the sum of legal costs which will influence the offer made.

Part (iii) of the proposition illustrates the importance of plaintiff risk aversion. Plaintiffs with smaller aversion to risk, as measured by the risk premium $r^{i}$, will receive larger settlement offers because they are more willing to resort to use of the risky court. If, as is frequently assumed, there is diminishing absolute risk aversion, wealthier plaintiffs will receive greater compensation for any given loss.

It is apparent from (5) to (7) that $V_{i N T P}, V_{a T P}$, and $V_{b T P}$ depend only on the difference between the offer and the loss. Equal changes in $S$ and $L$ will have no effect on the plaintiff's expected utility from a trial or from accepting the defendant's offer. $V_{i N T}$ is an increasing concave function of $S-L . V_{a T P}$ is unaffected by $S-L$ and $V_{b T P}$ is a decreasing function of $S-L$ for $e_{1}>S-L>e_{0}$. Figures 1 and 2 graph $V_{i N T P}, V_{a T P}$ and $V_{b T P}$ against $S-L$. In Figure 1 we have $S^{a}<S^{b}<S^{l}$ where $S^{l}$ satisfies $V_{a T P}=V_{b T P}$. $S^{l}$ is the offer which yields the same expected utility of a trial under both legal rules. In Figure $2 S^{a}>S^{b}>S^{I}$. It is obvious from the graphs that these two cases, plus the knife-edge case where $S^{a}=S^{b}=S^{l}$, are the only possible configurations of $S^{a}, S^{b}$ and $S^{l}$.

Several of the parts of proposition 2 can be illustrated with the Figures. For example, increases in $C_{D}$ and $C_{p}$ will shift $V_{b T P}$ downwards thereby reducing $S^{b}$. The Figures also emphasise the importance of examining the effect of a change in the legal rules on the actual offer made, rather than on the plaintiff's expected utility at a given offer. In Figure 1, for example, the plaintiff is better off, for given $S$, under British rules when $S<S^{I}$ but his gain arising from a change to British rules is less then the difference between $V_{b T P}$ and $V_{a T P}$ at $S^{a}$, because the change in rules leads to a reduction in the offer. 
Figure 1: Plaintiff prefers British rule.

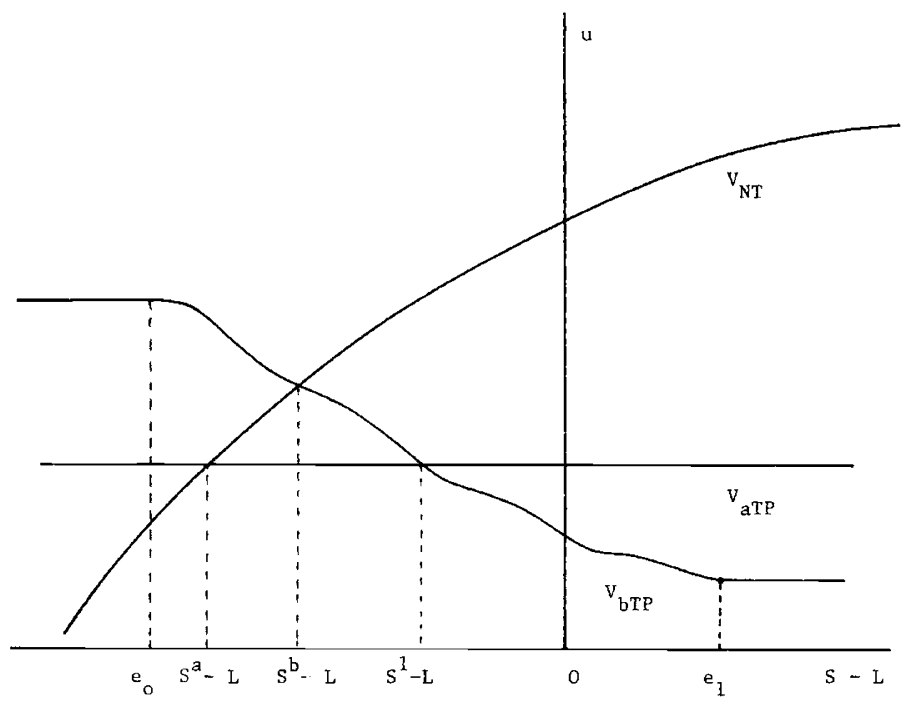

Figure 2: Plaintiff prefers American rule.

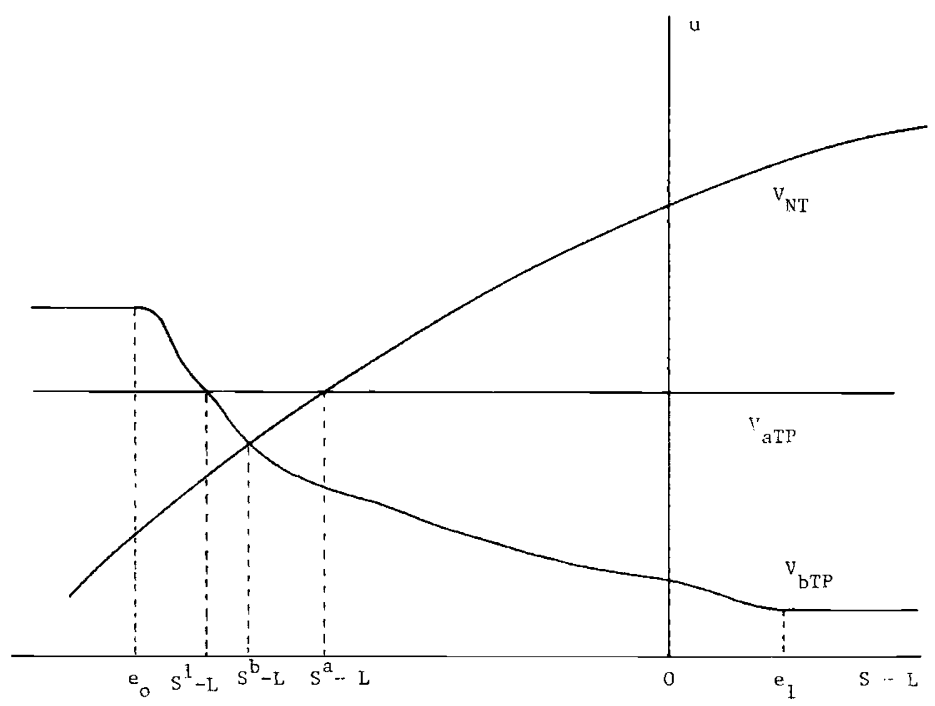




\section{Comparison of $S^{a}$ and $S^{b}$} ment is

Using (9) and (12) the impact of a change in the legal cost allocation rules on the settle-

$$
S^{a}-S^{b}=g^{b}-g^{a}=F\left(S^{b}-L\right)\left[C_{P}+C_{D}\right]+r^{b}-C_{P}-r^{a}
$$

This expression may be positive (as in Figure 2) or negative (Figure 1) or zero. Without fairly severe restrictions on preferences, the distribution function of court errors and on legal costs it is not possible to say whether the American or British rules lead to larger offers being made by the defendant.

Proposition 3: If (a) the defendant's legal costs do not exceed those of the plaintiff $\left(C_{D} \leq C_{P}\right)$, (b) the median court error is not less than the mean error $(F(E e)=F(0)$ $<1 / 2)$ and $(c)$ the plaintiff is risk neutral, then the settlement offer is larger under British rules than under American rules $\left(S^{b}>S^{a}\right)$.

Proof: Consider (15). Since $S^{b}<L$ (see Proposition 2) condition (b) implies that $F\left(S^{b}-L\right.$ ) $<1 / 2$. Together with condition (a), this implies that $F\left(S^{b}-L\right)\left[C_{P}+C_{D}\right]<C p$ and since, by risk neutrality (c) $r^{a}=r^{b}=0,(15)$ indicates that $S^{a}<S^{b}$.

Remarks: This proposition is stated in very similar form in Phillips, Hawkins and Flemming $[1975]^{9}$ and emphasises the importance of the plaintiff's attitude to risk. The assumptions about legal costs may be reasonable, or at least not wildly unreasonable. Since the court's error must always be bounded below (by $-\mathrm{L}$ ) but need not be bounded above, the requirement that the distribution of court errors is symmetric or positively skewed is also not too restrictive. Risk neutrality is probably not plausible in many cases where plaintiffs are exposed to large losses but may be sensible if the accident victim is fully insured and his right to compensation is taken over by his risk neutral insurance company under subrogation.

The effect of a change in legal rules on the defendant's offer, and hence on the plaintiff's expected utility, will depend on the plaintiff's degree of risk aversion. A change in rules from American to British affects the plaintiff's expected trial utility and thus his willingness to accept an offer in two ways. There is a greater dispersion in the plaintiff's post-trial income and expected post-trial income may be increased or decreased. The net effect on expected post-trial utility on an increase in dispersion and a change in expected income will depend on rather fine details of the plaintiff's preferences.

We show this by considering the effect of a change in the rules on the risk premium for the risky prospect of trial.

Proposition 4. If (a) the plaintiff's expected income is increased (decreased) by a change

to British rules and $(b)$ if the plaintiff has non-decreasing (non-increasing) absolute risk aversion, then the risk premium is larger under British rules.

Proof. A change from American to British rules changes the plaintiff's expected income if there is a trial by $C_{P}-F\left(S^{b}-L\right)\left[C_{P}+C_{D}\right]$. Define $y^{b} \equiv y-C_{P}+F\left(S^{b}-L\right)\left[C_{P}+C_{D}\right]$. The risk premium for a British trial with the plaintiff facing an offer of $S^{b}$ and having an endowed gross income of $y^{b}$ is

$$
r^{b}\left(y^{b}, S^{b}-L, C_{P}+C_{D}\right)=y^{b}-F\left(S^{b}-L\right)\left[C_{P}+C_{D}\right]-u^{-1}\left(V_{b T P}\left(y^{b}, S^{b}-L, C_{P}+C D\right)\right)
$$

${ }^{9}$ Phillips, Hawkins and Flemming [1975] use a very similar set of assumptions but do not consider the efficiency implications of the rules. 
The risk premium for an American trial if the plaintiff's endowed gross income is $y$ is

$$
r^{a}\left(y-C_{P}\right)=y-C_{P}-u^{-1}\left(V_{a T P}\left(y-C_{P}\right)\right)
$$

A change to British rules accompanied by a change in endowed gross income to $y^{b}$ will leave mean post-trial income unaffected and is a mean-preserving spread in the sense of Rothschild and Stiglitz [1970]. Hence $V_{b T P}\left(y^{b}, S^{b}-L, C_{P}+C_{D}\right)$ is less than $V_{a T P}\left(y-C_{P}\right)$ and $r^{b}\left(y^{b}\right.$, $\left.S^{b}-L, C_{P}+C_{D}\right)>r^{a}\left(y-C_{P}\right)$. Finally, if $C_{P}-F\left(S^{b}-L\right)\left[C_{P}+C_{D}\right]>(<) 0$, so that expected posttrial income is larger (smaller) under British rules and if absolute risk aversion is nondecreasing (non-increasing) then $r^{b}\left(y, S^{b}-L, C_{P}+C_{D}\right)>r^{b}\left(y^{b}, S^{b}-L, C_{P}+C_{D}\right)>r^{a}\left(y-C_{P}\right)$.

Remarks: Even if the risk premium is larger for British than American trials and the effect of the trial cost allocation rules on expected income is known, it may not be possible to deduce whether the plaintiff is better off under British or American rules. If expected income is reduced under British rules and absolute risk aversion is not increasing, proposition 4 indicates that $r^{a}<r^{b}$ and, from (15), $S^{a}>S^{b}$. For expected income to be lower under British rules requires either that $C_{D}$ be large relative to $C_{P}$ or that the error distribution of court awards be highly negatively skewed. If the distribution of errors is symmetric and $C_{D}$ $<C_{P}$, expected income is larger under British rules. If absolute risk aversion is increasing or constant, the British risk premium is greater than the American risk premium. The difference between $S^{a}$ and $S^{b}$ in (15) is then ambiguously signed, even though $r^{b}-r^{a}$ is positive, because $F\left[C_{P}+C_{D}\right]-C_{p}$ is negative (mean income has increased). If absolute risk aversion is decreasing, the risk premium could be reduced by a change to British rules (so that $S^{b}>$ $\left.S^{a}\right)$ but more detailed knowledge of risk preferences is necessary to reach definite conclusions.

The settlement offers depend on the income of the plaintiff and so the distribution of income amongst plaintiffs may be relevant in assessing the two allocation rules. Poor plaintiffs may get higher offers under one system. It is possible to show in one case that the larger is the plaintiff's income, the more likely is it that he is better off with the British cost allocation rules.

Proposition 5. If the plaintiff has diminishing absolute risk aversion and there exists an income $y^{\circ}$ such that he is indifferent between the cost allocation rules, then he would prefer the British rules at all higher incomes and the American rules at all lower incomes. The converse applies with increasing absolute risk aversion and with constant absolute risk aversion he is indifferent at all incomes.

Proof: At $y^{\circ}$ a change from American to British rules is an expected utility preserving spread in the sense of Diamond and Rothschild [1974] and the result is an immediate consequence of their Theorem 3.

Remarks: Decreasing absolute risk aversion or risk neutrality are usually thought to be more plausible restrictions on preferences than increasing absolute risk aversion. If risk aversion is decreasing a change from the American to the British system may be distributionally regressive. With decreasing risk aversion plaintiffs with lower incomes may be better off under American rules whilst those with higher incomes would prefer British rules. 


\section{Accident probabilities under American and British rules}

The defendant can control the probability of an accident $\pi$ by varying expenditure $x$ on care. The defendant has a post-accident cost of $S^{i}=L-g^{i}$ and he will choose care to maximise $-x-\pi(x)\left(L-g^{i}\right)$. The care level chosen $x^{i}$ will satisfy. ${ }^{10}$

$$
-1-\pi^{\prime}(x)\left(L-g^{i}\right)=0
$$

Proposition 6. The defendant takes more care and the accident probability is smaller, the larger is the settlement offer: $\partial x^{i} / \partial S^{i}>0$.

Proof: The proposition follows immediately from the strict convexity of $\pi(x)$, the first order condition (18) and $S^{i}=L-g^{i}$.

Remarks: The defendant's settlement offer is always accepted after an accident and his post accident cost is $S^{i}$. We can use the discussion of the settlement offers in the previous section to derive a number of corrollaries to proposition 6 . For example: a $\$ 1$ income in $L$ leads to a $₹ 1$ increase in $S^{i}$ (Proposition 2) and so the defendant takes more care the greater is the accident loss. Whatever the allocation rules the defendant's response to increases in the social cost of an accident is at least not perverse even though he does not bear all the accident costs.

\section{Expected pre-accident utilities}

The rules must not be judged solely by their effect on the expected utilities of the parties after an accident has occurred. The rules alter the care taken by the defendant to avoid an accident as well as the offer he makes if an accident occurs. The rule which leads to the larger post-accident offer will also generate the greater amount of care by the defendant. Unfortunately, as we saw above, it is not clear which rule leads to the larger settlement offer. It is possible to establish that the parties will never agree on which is the better rule.

Proposition 7. If the plaintiff prefers the British (American) rule the defendant will prefer the American (British) rule.

Proof: Since $x^{i}$ maximes $-x-\pi(x) S^{i}$ we have

$$
\mathrm{V}_{\mathrm{iD}}=-x^{i}-\pi\left(x^{i}\right) S^{i}>-x j-\pi\left(x^{j}\right) S^{i}
$$

and if $S^{i}<S i$

$$
-x^{j}-\pi(x) S^{i}>-x^{i}-x\left(\pi^{i}\right) S j=V_{j D}
$$

so that $S^{i}<S^{j}$ is equivalent to $V_{i D}>V_{j D}$. The plaintiff's utility after an accident, given that he is made a just acceptable offer, is $V_{i T P}=u(y-L+S i)<u(y)$. His expected utility is $V_{i P}=$ $\left[1-\pi\left(x^{i}\right)\right] u(y)+\pi\left(x^{i}\right) V_{i T P}$ and so

$$
V_{i P}-V_{j P}=\pi(x j)\left[u(y)-V_{j T P}\right]-\pi\left(x^{i}\right)\left[u(y)-V_{i T P}\right]
$$

But $S^{i}<S^{j}$ if and only if $\pi\left(x^{i}\right)>\pi\left(x^{j}\right)$ (Proposition 6) and thus (19) is negative if and only if $V_{i D}>V_{j D}$.

${ }^{10} \mathrm{We}$ assume that $S^{i}$ will always be large enough to yield a positive level of care. The second order condition is satified because of the convexity of $\pi$. 
Remarks: The fact that the rules have opposite effects on the expected utilities of the parties means that a change from one set of rules to the other will never produce a Pareto improvement. The policy choice between the rules will inevitably involve judgements about the social value of changes in the expected utility of defendants and plaintiffs.

\section{Welfare}

First and second best care

A first best resource allocation is characterised by efficient care and efficient risk bearing or insurance. ${ }^{11}$ Efficient risk bearing requires that the plaintiff's marginal utility of income is the same whether or not an accident occurs. With a risk averse plaintiff whose marginal utility is state independent, efficient risk bearing implies full compensation of the plaintiff $\left(S^{i}=L\right)$. The first best care level minimises the sum of expenditure on care expected accident losses $[x+\pi(x) L]$.

If the imperfect legal system is the only feasible method of compensating the plaintiff the second best care level maximises the social welfare function:

$$
W=-x-\pi(x) S^{i}+\lambda\left[(1-\pi(x)) u(y)+\pi(x) V_{i T P}\right]
$$

where $\lambda$ is a positive weight reflecting distributional value judgements. The second best care level $x^{*} i$ will depend on the legal cost allocation rules and satisfies

$$
0=-1-\pi^{\prime}\left(x^{*}\right)\left[S^{i}+\lambda\left(u(y)-V_{i T P}\right)\right]
$$

If we make the distributional neutrality assumption

$$
\lambda^{-1}=(1-\pi) u_{y}(y)+\pi u_{y}\left(y-g^{i}\right)\left(1-d g^{i} / d y\right)
$$

then we are indifferent as to whether an addition $£ 1$ accrues to defendant or plaintiff. (Remember that $V_{i T P}=u\left(y-g^{i}\right)$ ).

Proposition 8. (i) Assuming distributional neutrality and a small accident probability, the second best care level is greater than the first best level if the plaintiff is risk averse.

(ii) With distributional neutrality and a risk neutral plaintiff the first and second best levels are identical.

Proof: (i) If $u(\cdot)$ is concave there exists a $y^{o}$ such that $u(y)-u\left(y-g^{i}\right)=g^{i} u_{y}\left(y^{o}\right)$ with $y-g^{i}<$ $y^{o}<y$. If (22) holds, then for small enough $\pi$, we have

$$
S^{i}+\lambda\left[u(y)-u\left(y-g^{i}\right)\right]=L+g_{i}\left[\lambda u_{y}\left(y^{o}\right)-1\right]
$$

As $\pi$ tends to zero $\lambda^{-1}$ tends to $u_{y}(y)$ and if $u$ is strictly convave $u_{y}(y)<u_{y}\left(y^{o}\right)$. Hence (23) exceeds $L$ and $x^{* i}$, defined by (21), exceeds the first best care $x^{* *}$ defined by $-1-\pi^{\prime}\left(x^{* *}\right) L$ $=0$. (ii) If $u$ is linear in income $u_{y}(y)=u_{y}\left(y^{o}\right)$ and (23) equals $L$.

11 A first best allocation would also have a zero probability of costly trials. In this model the defendant always makes an acceptable offer and no trial takes place. Gravelle [1987] considers a model in which trials have a non-zero probability. 
Remarks: The full cost of the accident is the damage plus the cost of risk borne by the plaintiff. Only if there is full compensation (perfect insurance), or if the plaintiff is risk neutral, will $L$ measure the social cost of accidents. Although trials are costly, $C_{P}$ and $C_{D}$ do not affect the social cost of an accident because the defendant's offer is always accepted and trials never take place. The litigation costs do influence the settlement but this is a transfer from the plaintiff to the defendant. If we make the distributional neutrality assumption the size of the post-accident transfer cannot affect the second best care level.

No assumptions on the accident probability or on the distributional weight (other than benevolence $(\lambda>0))$ are necessary to establish.

Proposition 9. Under American and British legal cost allocation rules the choice of care is less than the second best level.

Proof: Since $u(y)>V_{i T P}=u\left(y+S^{i}-L\right)=u\left(y-g^{i}\right)$ and $\lambda>0, S^{i}+\lambda\left(u(y)-u\left(y-g^{i}\right)\right)>S^{i}$. Compare (18) and (21).

Remarks: The defendant bears less than the full cost of the accident since $S^{i}=L-g^{i}<L$. His offer is less than sufficient to fully compensate the plaintiff and he takes too little care. The settlement makes the plaintiff indifferent between a trial and no trial, whereas for efficiency it should make him indifferent as to whether the accident occurs.

\section{Policy alternatives}

Policy makers may have a variety of options in attempting to improve the efficiency of resource allocation. The courts could adjust their awards upwards so that $L_{J}=L+\alpha+e$ with $\alpha>0$. This would increase the plaintiff's willingness to proceed to trial and so increase the defendant's offer. The offer could similarly be increased by subsidising the plaintiff's legal costs since this will again increase his willingness to reject the defendant's offer. ${ }^{12}$

Proposition 10. A first best allocation is achievable by (i) increases in court awards or (ii) by subsidisation of the plaintiff's legal costs.

Proof: (i) $V_{i T P}$ increases with $\alpha$, so there always exist $\alpha^{i}$ such that $V_{i T P}=u(y)$. Such an $\alpha^{i}$ produces offers of $S^{i}=L$, where $V_{i N T P}=u\left(y+S_{i}-L\right)=u(y)$, since $S^{i}$, which is the lowest offer which avoids a trial, still saves the defendant $C_{D}$ compared with the expected trial outcome. Inspection of (6), (7) shows that $\alpha^{a}=C_{P}+r^{a}$ and $\alpha^{b}=F\left(-\alpha^{b}\right)\left[C_{P}+C_{D}\right]+r^{b}$. With $S^{i}=L$ the plaintiff is fully compensated and the defendant chooses first best care. (ii) If a subsidy $\beta^{i}$ is paid towards the plaintiff's legal costs of a trial then $S^{a}=L-C_{P}-r^{a}\left(y-C_{P}+\beta^{a}\right)$ $+\beta^{a}$ and $S^{b}=L-F\left[C_{P}-\beta^{b}+C_{D}\right]-r^{b}$. Setting $\beta^{a}=C_{P}+r^{a}$ and $\beta^{b}=C_{P}+C_{D}+r^{b / F}$ ensures $S^{i}=L$ and first best risk sharing and care.

Remarks: If the defendant must fully compensate the plaintiff for accident losses he will take account of them appropriately in his choice of care. When the plaintiff's right to compensation can only be exercised through the courts at a cost to the plaintiff, the defendant's strict liability for damage is not sufficient to ensure efficient behaviour. If the plaintiff's propensity to take legal action can be increased by increased awards or subsidised legal costs the first best allocation can be achieved without any need to influence care choices

12 Since our interest is in the effect of the legal system on efficiency we will restrict attention of legal procedural policy instruments. Subsidies to care will clearly increase care towards the second best level for example. We assume that care is not observable by the policy maker. 
directly. ${ }^{13}$ In these circumstances the legal cost allocation rules are of significance only because they affect the precise levels of $\alpha$ or $\beta$ required for first best. The first best can be achieved under either rule by appropriate adjustments to the award or subsidy to the plaintiff.

\section{Third best policy: choice of cost allocation rules}

When court awards and legal costs are not alterable, policy may be reduced to a choice of cost allocation rules. Such a choice will lead to a "third best" allocation in which the maximum possible social welfare is less than the second best level. Further, it will not be possible to determine which legal cost allocation rule leads to greater social welfare without very precise information.

To show this it is instructive to introduce the plaintiff's risk premium $R^{i}$ for the compound prospect of an accident and a risky trial. We define $R^{i}$ by

$$
R^{i}=y-\pi(x) g^{i}-u^{-1}\left[(1-\pi) u(y)+\pi u\left(y-g^{i}\right)\right]
$$

since $y-\pi g^{i}=y-\pi\left[L-S^{i}\right]$ is expected income and $u\left(y-g^{i}\right)=V_{i T P}$. Replacing $(1-\pi) u(y)+$ $\pi V_{i T P}$ in the social welfare function (20) with its certainty equivalent, and making the distributional neutrality assumption that $£ 1$ increases in the defendant's and plaintiff's certainty equivalent incomes have the same marginal social value, the social welfare function can be written

$$
W^{i}=-x^{i}-\pi S^{i}+y-\pi g^{i}-R^{i}=y-x^{i}-\pi L-R^{i}
$$

The effect of a change from British to American rules is

$$
W^{a}-W^{b}=x^{b}-x^{a}+L\left[\pi\left(x^{b}\right)-\pi\left(x^{a}\right)\right]+R^{b}-R^{a}
$$

Inspection of (24) shows that even if we know whether $S^{a}<S^{b}$ (as in Figure 1) or $S^{a}>S^{b}$ (as in Figure 2) and hence know the relative magnitudes of $\left(g^{a}, g^{b}\right),\left(x^{a}, x^{b}\right)$ and $\left(V_{a T P}, V_{b T P}\right)$ it is not possible to sign (25).

In one simple case it is possible to indicate which rule is preferable.

Proposition 11. If the plaintiff is risk neutral then the rule which leads to the larger settlement offer yields greater social welfare

Proof: With risk neutrality $R^{a}=R^{b}=0$ and $W^{i}=-x^{i}-\left(x^{i}\right) L$. The socially optimal care level, which is the same under both regimes, satisfies $-1-\pi^{\prime}\left(x^{* *}\right) L=0$. The privately optimal $x^{i}$ satisfy $-1-\pi^{\prime}\left(x^{i}\right)\left(L-g^{i}\right)=0$. Since $\pi$ is convex in $x, x^{i}<x^{* *}$ and $d W / d x>0$ at $x^{i}$. Thus $W^{a}>W^{b}$ if and only if $x^{a}>x^{b}$ which is equivalent to $g^{a}<g^{b}$ and thus to $S^{a}>S^{b}$.

Remarks: With a risk neutral plaintiff and distributional neutrality we are concerned only with the expected accident losses, not with how they are shared between plaintiff and defendant. Since the privately optimal care is determined by the defendant's share of the accident losses, the set of rules which makes this share larger provides the more appropriate incentives for care. If propositions 8 and 3 are combined we see that with a risk neutral plaintiff, a symmetric distribution of court errors and equal legal costs the British legal cost allocation rules generate a more efficient level of care.

13 Polinsky and Rubinfeld [1988] also show that it may be possible to achieve a first best by suitable adjustment to the court award but do not consider different legal cost allocation rules. 


\section{Conclusions}

The model used in this paper was simplified to focus on the effect of the rules. Since no clear conclusion about the relative merits of the rules emerges from a simple specification, more complex and realistic models are unlikely to modify the basic result of the paper that a great deal of detailed information is necessary to identify the better of the rules.

\section{REFERENCES}

BEBCHUK, L. A. [1984]: "Litigation and settlement under imperfect information", Rand Journal of Economics, 15 (Autumn 1984), 404-415.

BRAEUTIGAN, R., OWEN, B. and PANZAR, J. [1984]: “An economic analysis of alternative fee shifting systems", Law and Contemporary Problems, 47 (Winter 1984), 173-185.

COASE, R.H. [1960]: "The problem of social cost", Journal of Law and Economics, 3 (October 1960), 1-44.

DIAMOND, P. A. and STIGLITZ, J. E. [1974]: "Increases in risk and in risk aversion", Journal of Economic Theory, 8 (1974), 337-360.

GRAVELLE, H. S. E. [1987]: "The efficiency implications of the allocation of litigation costs", Queen Mary College Discussion Paper in Economics, No. 168, (November 1987).

ORDOVER, J. A. [1981]: "On the consequences of costly litigation in the model of single activity accidents: some new results”, Journal of Legal Studies, 10 (June 1981), 269-291.

PHILLIPS, J., HAWKINS, K. and FLEMMING, J. [1975]: “Compensation for personal injuries”, Economic Journal, 85 (March 1975), 129-134.

PNG, I. P. L. [1987]: "Litigation, liability, and incentives for care", Journal of Public Economics, 34 (October 1987), 61-85.

POLINSKY, A. M. [1980]: "Strict liability vs negligence in a market setting", American Economic Review, 70 (May 1980), 363-367.

POLINSKY, A. M. and RUBINFELD, D. L. [1988]: "The welfare implications of costly litigation in the theory of liability", Journal of Legal Studies, 17 (January 1988), 151-163.

PRATT, J. W. [1964]: "Risk aversion in the small and in the large", Econometrica, 32 (January-April 1964), 122-136.

ROTHSCHILD, M. and STIGLITZ, J. E. [1970]: "Increasing risk I: A definition”, Journal of Economic Theory, 2 (1970), 225-243.

SHAVELL, S. [1982a]: "Suit, settlement and trial: A theoretical analysis under alternative methods for the allocation of legal costs", Journal of Legal Studies, 11 (January 1982), 55-81.

SHAVELL, S. [1982b]: "The social versus private incentive to bring suit in a costly legal system", Journal of Legal Studies, 11 (June 1982), 333-339.

SIMON, M. J. [1984]: "Product quality and allocation of legal costs", U. S. Department of Justice, Economic Policy Office Discussion Paper, EPO 84-4, (May 22nd 1984). 